\title{
Variations of two temporal parameters in observing response procedures
}

\author{
STEPHEN B. KENDALL \\ University of Western Ontario, London, Ontario N6A 5C2, Canada
}

\begin{abstract}
Temporal parameters were varied in two different observing response procedures. In Experiment I, concurrent variable-interval chain schedules were employed. Responding on one key led to either a stimulus correlated with reinforcement or a stimulus correlated with time-out. Responding on the other key led to a stimulus which ended either in reinforcement or time-out. The duration of the delay to reinforcement or time-out was varied, the delays for all three stimuli always remaining equal in a given phase. It was found that the longer the delay, the greater the preference for the observing response. In Experiment II a procedure was employed in which birds pecked during a "trial" to produce stimuli correlated with reinforcement or time-out at the end of the trial. The duration of the trial ending in time out was varied while the positive trial duration remained constant. It was found that the longer the duration of the negative trial, the greater the strength of observing responses. The results were interpreted as supporting the hypothesis that the value of a positive stimulus is a function of time spent in stimuli correlated with nonreinforcement.
\end{abstract}

Certain effects of manipulating temporal parameters in observing response procedures may be of considerable interest. Wilton (1972) has predicted that the longer the duration of the differential stimuli in an observing response procedure, the greater the information in the stimuli will add to the reinforcing value of the stimuli. In his words, "when the transmitting stimulus occurs at some distance before the goal the information contained in it increases the reinforcing strength of the stimulus by a relatively greater amount than if the stimulus were nearer to the goal" (Wilton, 1972, p. 479). Wilton emphasizes that it is the stimulus correlated with reinforcement that reinforces the observing response, and not both of the stimuli produced by the observing response procedure.

Only minimal evidence is available on this point. Lutz and Perkins (1960) studied the acquisition of observing responses in an $\mathrm{E}$ maze where a turn in one direction produced stimuli correlated with reinforcement in a delay box. A turn in the other direction produced nondifferential stimuli in the delay box. They found that if there was no delay (the animals were allowed to run straight through the delay boxes), there was no preference for the side with correlated stimuli. Any delay from 3 to $81 \mathrm{sec}$ produced a preference for the observing response, but there was no difference between the various delay groups except the difference between $0 \mathrm{sec}$ and all other delays. McMichael, Lanzetta, and Driscoll (1967) found an increased preference for the observing response in a two-lever observing response procedure similar to Lutz and Perkins. There, investigators did not study the effects of delay systematically, however.

This research was sponsored by a grant from the National Research Council of Canada. Reprints may be obtained from the author, Department of Psychology, University of Westem Ontario, London, Ontario, Canada N6A $5 \mathrm{C2}$.
Another temporal manipulation that is of interest is to change the duration of the negative or less preferred stimulus independently of changes in the positive or more preferred stimulus. A number of experiments have demonstrated that manipulations of the probability of the components produces changes in the strength of observing responses. If the negative, or less valued, component is more probable, then the positive observing responses may be stronger than if the more valued component is more probable than the less valued (Eckerman, 1973; Kendall, 1973b; McMichael et al., 1967; McMillan, 1970; Wilton \& Clements, 1971; Hendry, Note 1). In all of these experiments, altering the probabilities of the different components alters the proportion of the session time that the animal spends in the presence of the components. For instance, decreasing the probability of the positive (or more highly valued) component increases the amount of time that the subject spends in the less valued component. Thus, these experiments confound component probability with time spent in a component. Since these experiments are basic to the interpretation of observing responses (Wilton, 1972), it is important to discover if altering temporal parameters may alter observing response strength without altering component probability.

The experiments reported here bear on the issues raised above. In Experiment I, the delay in the presence of all stimuli (positive, negative, and mixed) was altered using a concurrent chains procedure similar to that used by Hursh and Fantino (1974) with variable-interval schedules used as first links. The second experiment manipulated the duration of the negative component using a procedure previously reported by Kendall (1973b). 


\section{EXPERIMENT I}

\section{Method}

Subjects. Subjects for the experiment were three female Silver King pigeons approximately 3 years old. All were experimentally naive.

Apparatus. The apparatus consisted of a Lehigh Valley Electronics pigeon chamber with two pecking keys. Each key required about $15 \mathrm{~g}$ of force to operate. The keys could be transilluminated by ESB Type 24-V bulbs. Colored caps over the bulbs produced red and green key colors used in the present experiment. The pigeon chamber was housed in a room with several other chambers. This room was provided with a white masking noise. Electromechanical programming and recording equipment was housed in an adjacent room.

Procedure. The birds were trained by the method of successive approximations (shaping) to peck at one of the response keys. During shaping, the response keys were dark. The reinforcer consisted of $3.5 \mathrm{sec}$ access to mixed grain. During the presentation of grain, the houselight was turned out and the light above the food hopper went on. These same stimulus conditions obtained throughout the experiment at the time of food delivery. When the birds had learned to peck on one of the keys, that key was covered and the bird was trained to peck the other.

Following shaping, the birds were exposed to a concurrent chains observing response procedure. In the initial component of the chains, both keys were dark. The schedule, in effect, was variable-interval $20 \mathrm{sec}$ on each key. When the variable-interval associated with a key had timed out, the next peck to that key produced the consequence associated with that key. One of the keys was designated the observing response key with the other being the nonobserving response. The consequence of pecking on the observing response key when the variable interval in the first link had timed out was the presentation of one of two key colors. Each color had a probability of .50 . If the key turned green, it remained green for the duration of the delay interval and then the grain hopper was presented for $3.5 \mathrm{sec}$. If the key turned red, it remained red for the delay interval, and was followed by a $3.5-\mathrm{sec}$ time-out. The delay interval was varied during the experiment but was always the same for red and green in any given phase of the experiment. Pecking on the other key led to the presentation of a white light. When that key turned white, it remained white for the delay interval and then either a time-out or food presentation occurred. The probability of food presentation following white was .50 . The delay in terval filled by the white light was varied during the experiment, along with the delay in red and green, but during any phase of the experiment the delay in green, red, and white was the same.

When one of the variable-interval timers had timed out, the next peck to that key produced the consequence associated with that key and the other key remained dark, but was inoperative. Since the variable intervals were in effect only in the initial component of the chains, both timers were stopped during a terminal component, regardless of which terminal component appeared.

The first delay studied in the terminal components was $15 \mathrm{sec}$. Following stabilization on this delay interval, three other delays were studied. These were 1,3 , and $7 \mathrm{sec}$. Each bird was exposed to these delays in a different order. The order of presentation and the number of sessions given a bird are presented in Table 1. Following exposure to these delays, all birds were reexposed to $15 \mathrm{sec}$ delay. As previously mentioned, the delays in white, green, and red always assumed the same value (i.e., 15, 7, 3, or $1 \mathrm{sec}$ ).

During the initial training on the concurrent chains procedure the birds were not immediately exposed to the $15 \sec$ delay. The delay was increased gradually from 1 to 15 sec over the course of about five sessions. Increases of 3 or $4 \mathrm{sec}$ per day were made.
Table 1

The Order of the Delay Conditions, Number of Sessions at Each Delay, Relative Response Rate on the Observing Key, and Absolute Response Rates on Each Key are Given

\begin{tabular}{|c|c|c|c|c|c|}
\hline \multirow{2}{*}{$\begin{array}{c}\text { Order of } \\
\text { Delays }\end{array}$} & \multirow{2}{*}{$\begin{array}{c}\text { Delay } \\
\text { Condi- } \\
\text { tion }\end{array}$} & \multirow{2}{*}{ Sessions } & \multirow{2}{*}{$\begin{array}{l}\text { Relative } \\
\text { Response } \\
\text { Rate on } \\
\text { Observ- } \\
\text { ing Key }\end{array}$} & \multicolumn{2}{|c|}{$\begin{array}{c}\text { Absolute } \\
\text { Rates }\end{array}$} \\
\hline & & & & Ro & Non Ro \\
\hline \multicolumn{6}{|c|}{ Bird 7} \\
\hline $15,7,1,3,15$ & $\begin{array}{r}1 \\
3 \\
7 \\
15\end{array}$ & $\begin{array}{l}18 \\
32 \\
20 \\
20^{*}, 20\end{array}$ & $\begin{array}{l}.56 \\
.59 \\
.94 \\
.90 \dagger\end{array}$ & $\begin{array}{l}32.36 \\
38.92 \\
33.21 \\
39.87\end{array}$ & $\begin{array}{r}25.08 \\
27.24 \\
2.06 \\
4.76\end{array}$ \\
\hline \multicolumn{6}{|c|}{ Bird 8} \\
\hline $15,1,7,3,15$ & $\begin{array}{r}1 \\
3 \\
7 \\
15\end{array}$ & $\begin{array}{l}15 \\
31 \\
25 \\
20^{*}, 23\end{array}$ & $\begin{array}{ll} & .59 \\
& .77 \\
& .68 \\
3 & .91 \dagger\end{array}$ & $\begin{array}{l}45.39 \\
57.88 \\
46.85 \\
55.35\end{array}$ & $\begin{array}{r}32.12 \\
17.70 \\
22.04 \\
5.92\end{array}$ \\
\hline \multicolumn{6}{|c|}{ Bird 9} \\
\hline $15,3,1,7,15$ & $\begin{array}{r}1 \\
3 \\
7 \\
15\end{array}$ & $\begin{array}{l}17 \\
24 \\
32 \\
20^{*}, 15\end{array}$ & $\begin{array}{ll} & .65 \\
& .76 \\
& .93 \\
5 & .97 \dagger\end{array}$ & $\begin{array}{r}49.16 \\
64.43 \\
112.35 \\
114.38\end{array}$ & $\begin{array}{r}26.62 \\
20.58 \\
8.78 \\
5.00\end{array}$ \\
\hline
\end{tabular}

Note-All data are the means of the last five sessions under a given condition.

* First exposure

tA verage of two exposures

During this training, the birds were matched for any key preference. If a key preference developed, the nonpreferred key was designated as the observing response key, since it was expected on the basis of previous research that there would be an overwhelming preference for the observing key (Bower, McLean, \& Meacham, 1966; Hendry, 1969).

\section{Results}

The dependent variable of this experiment was the relative rate of responding on the observing key. This is defined as the rate on the observing response key divided by the rate on both keys. The relative rate was taken as an indication of "preference."

Figure 1 displays the relative rate on the observing key as a function of delay. Individual data for all three birds is shown. For the individual birds, each datum point is the mean of the last five sessions under a given condition. Since the birds were exposed twice to the $15 \mathrm{sec}$ delay, the points at $15 \mathrm{sec}$ are the means of the last five sessions of both exposures. The data are also given in Table 1.

Generally, as the delay increased, preference for the observing response also increased. The data for Bird 8 showed a reversal of this trend at $7 \mathrm{sec}$, but apart from this, the data are consistent and reasonably orderly. The relative rates at $1 \mathrm{sec}$ vary between .55 and .65 and between .90 and 1.00 at $15 \mathrm{sec}$. Relative rates as high as .90 show a very strong preference for the observing response, especially since the potential rates of reinforcement were equal for responding on the two 


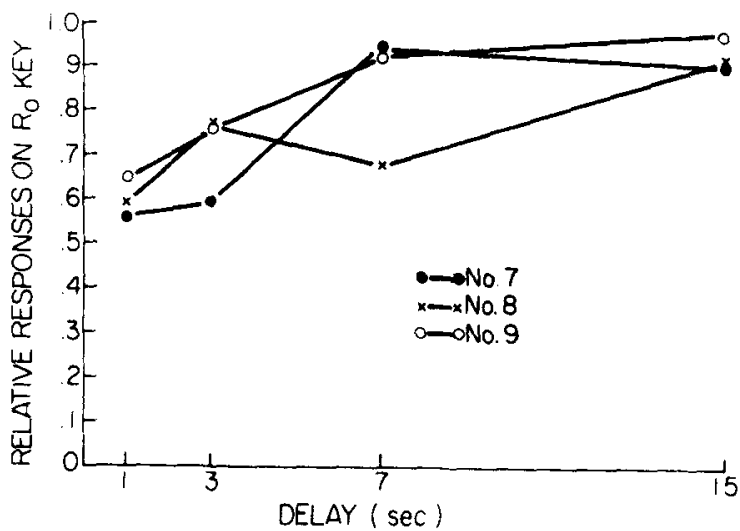

Figure 1. Relative rate of responding on the observing key for the three subjects under all delays. The data points for the 15-sec delay are averages of the first and last exposure.

keys.

Table 1 shows the relative rates for each bird under each delay condition. In addition, the absolute rates under each condition are given. Examination of these indicates that generally there was a rate decrease on the nonobserving response key as the delay increased. For two of the birds, there was not very much change in response rate on the observing response key as the delay increased. For these two, there does not seem to be any very consistent trend with increasing delay. For the other bird (Bird 9) there was a consistent increase in observing response rate as the delay increased. This change was fairly sizable.

\section{EXPERIMENT II}

Experiment I showed that increasing the delay to reinforcement or time-out in an observing response procedure increases the preference for the observing response. Experiment II was concerned more specifically with the amount of time during a session that was spent in the presence of the negative component, in which no food was delivered. A different experimental procedure was involved in which food was delivered "free" on some trials and a time-out on others. By making an observing response, stimuli correlated with food trials or time-out trials would be presented. The independent variable was the duration of the negative component.

\section{Method}

Subjects. The subjects were six female White Carneaux pigeons obtained from Palmetto Pigeon Plant. They were between 2 and 4 years old when the experiment was conducted. Two of the birds had been used in previous observing response experiments and four were experimentally naive. They were designated as Birds $1,2,3,4,5$, and 6 . Birds 5 and 6 were the nonnaive birds.

Procedure. The basic procedure was as follows: The pigeons were given 60 trials per experimental session. A trial consisted of a period of 30 sec during which the houselight was illuminated.
The response key remained dark during a trial unlcss it was pecked a given number of times (fixed-ratio schedule). A trial could terminate in either a 3.5-sec period in which the grain hopper was raised (food delivery) or a time-out of the same duration. During the time-out, the houselight went out and the chamber was dark. The houselight also went off during food delivery. Half of the trials terminated in food delivery, and half in time-out in an irregular sequence. Another feature of the trial was a DRO contingency during the final $2 \mathrm{sec}$ of a trial. If a bird pecked during the last $2 \mathrm{sec}$, a timer was reset which prolonged the end of the trial for an additional 2 sec. Further pecks continued to reset the timer and delay the end of the trial. A failure to peck during a trial in no way affected the trial except that the key remained dark until the trial terminated.

Pecking during a trial produced one of a pair of stimuli. The stimuli were colored lights behind the response key, presented by a projector mounted behind the key. Two colors were used-red and green. If the trial was positive, ending in food delivery, the color resulting from pecking was green. If the trial was negative, terminating in time-out, the color produced was red. Once the bird had pecked and turned on one of the stimuli, the key remained lit until food delivery or time-out. Following food delivery or time-out, the key was dark. This defined the beginning of a new trial.

Birds $1,2,3$, and 4 trained on a fixed ratio of three responses (FR 3). Three pecks during a trial turned on the stimulus correlated with that trial. Following 15 sessions of this training, the duration of the negative trial was shortened to $10 \mathrm{sec}$ for Birds 1 and 2 and lengthened to $50 \mathrm{sec}$ for Birds 3 and 4 . The duration of the positive trial remained at $30 \mathrm{sec}$. The birds were trained at the new condition for 15 sessions.

Following this phase, Birds 1 and 2 were returned to equal 30 -sec trials but with FR 1 in effect. Birds 3 and 4 were also returned to equal 30-sec trials but with FR 6 in effect. The birds were trained under these conditions for between 15 and 20 sessions, then the duration of negative trials was altered to $10 \mathrm{sec}$ for Birds 1 and 2 and positive trials were $30 \mathrm{sec}$. Birds 3 and 4 were reexposed to 50 -sec negative trials and $30-\mathrm{sec}$ positive trials.

Prior to these experimental manipulations, these birds were trained on the basic observing response procedure, described above. Training consisted of first shaping a keypeck by the method of successive approximations. Food was used as the reinforcer during shaping. When a few reinforced pecks had been emitted, the trial procedure was instituted, but the duration of the trials were $2 \mathrm{sec}$. Trials were gradually lengthened over a period of five sessions to $30 \mathrm{sec}$. Intermediate trial durations were 5,10 , and $20 \mathrm{sec}$.

Birds 5 and 6 had previously participated in observing response experiments and needed no preliminary training. They were exposed to negative trial durations of 15,30 , and $50 \mathrm{sec}$, with positive trial duration kept at $30 \mathrm{sec}$. One bird underwent the sequence of negative trial durations in ascending order and one in descending order. Between 15 and 20 experimental sessions were given in each condition.

\section{Results}

There are two dependent variables which are displayed in the figures. One is the relative frequency of observing responses. An "observing response" is the completion of a fixed ratio, whatever its value, and the resulting production of a stimulus. Since an observing response could occur or not occur on any trial, the number of observing responses divided by the total number of trials provides one measure of observing response output. The other dependent variable is response rate. This is the number of keypecks divided by 
the amount of time the bird spent in the presence of the dark key. Neither pecks at the key nor time spent in the presence of response-produced stimuli were counted in computing rate.

Figure 2 shows relative frequency and response rate for Birds 1, 2, 3, and 4 when the ratio value was FR 3 for all birds. Both measures dropped for both Birds 1 and 2 when the duration of the negative trial was altered from 30 to $10 \mathrm{sec}$. The birds were responding on almost every trial when the negative trial was $30 \mathrm{sec}$. Both dropped considerably when the negative trial was 10 sec. Similarly, the response rate for both birds decreased when this change was made. The data for the other birds, 3 and 4, are neither so clear nor so consistent. The relative frequency was somewhat higher for Bird 3 under the 50-sec negative duration condition, but Bird 4 was already responding on almost all trials and could not show very much increase. The response rates for these birds went in opposite directions. For Bird 3, the response rate increased when the negative trial was increased; for Bird 4, it decreased.

Figure 3 shows the results from the second phase for these four birds. Birds 1 and 2 were reexposed to the same conditions as previously, but with FR 1 instead of FR 3. The reason for this was that there was a possibility that FR 3 was too large for the 10-sec trial, so that
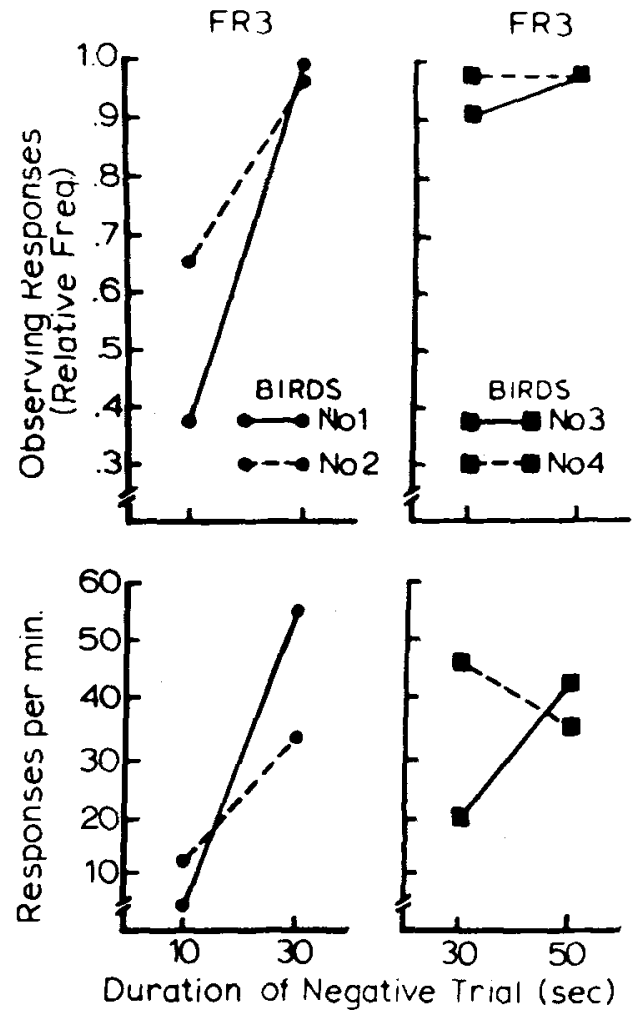

Figure 2. Relative frequency (upper panels) and response rate (lower panels) of observing responses as a function of negative trial duration for Birds 1, 2, 3, and 4. All birds were on FR 3 .
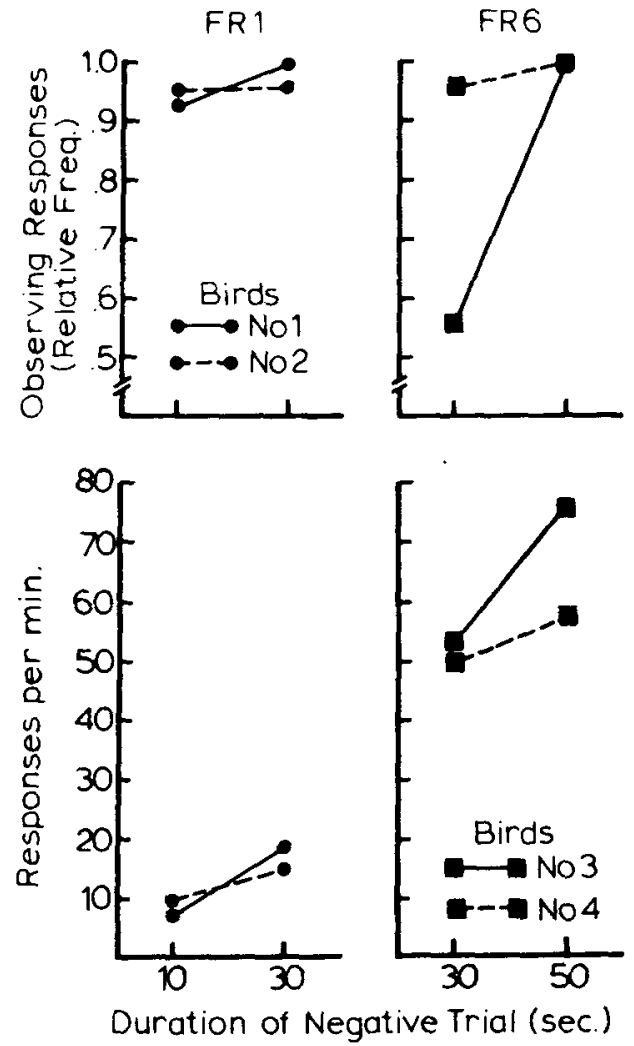

Figure 3. Relative frequency (upper panels) and response rate (lower panels) of observing responses as a function of negative trial duration for Birds 1, 2, 3, and 4. Birds 1 and 2 were on FR 1 and Birds 3 and 4 were on FR 6.

responses did not occur fast enough on negative trials to produce a stimulus before the trial ended. There is not much to suggest this is true since birds can easily respond several times per second. In addition, this hypothesis would predict an immediate drop when the duration of the trial was shortened from 30 to $10 \mathrm{sec}$. This immediate drop did not occur. When the ratio was FR 3, Bird 1 made 30 observing responses on negative trials on the last day that the negative stimulus was $30 \mathrm{sec}$. This bird made 30 observing responses on negative trials on the 1st day of the 10-sec negative-trial condition. The numbers of Bird 2 were 27 on the last day of the $30-\sec$ negative-trial condition and 27 on the 1 st day of the 10-sec condition. In spite of these arguments, it seemed wise to repeat the procedure with as small a ratio as possible.

Since the data were inconsistent for Birds 3 and 4, it was decided to repeat the procedure for these birds also. It was hoped that increasing the ratio would increase the sensitivity of the behavior to changes in the negative trial duration.

For Birds 1 and 2, the response rate dropped when they were switched from $30-\mathrm{sec}$ to $10-\mathrm{sec}$ negative-trial durations. The relative frequency dropped slightly for Bird 1 but not for Bird 2. Also note that the response 
rate is much lower for FR 1 than for FR 3 (in Figure 2) at a negative-trial duration of $30 \mathrm{sec}$. This is probably an artifact of the procedure for computing response rate. When birds respond on a fixed ratio, it probably does not take too much more time to emit three pecks than it does one so that most of the time entered in the calculation is the "latency" or time from the onset of a trial to the first peck.

The data for Birds 3 and 4 were in the same direction with the ratio at FR 6 , but the magnitude of the effect of lengthening a trial was much greater for Bird 3 than for Bird 4. However, both birds showed some increase in relative frequency and response rate measures when the duration of the negative trial was increased.

Data for Birds 5 and 6 are presented in Figure 4. The trend for both relative frequency and rate measures is summarized by saying the shorter the negative trial the weaker the observing response. The relative frequency data, however, do not show very substantial changes for either bird. Response rate does change for both birds, in the direction just mentioned. Note, however, that there is no change for Bird 6 between the 15- and 30-sec negative-trial conditions. There is a large change between the 30- and 50-sec negative trial conditions for this bird.

The data of the present experiment show that the duration of the negative trial relative to the duration of the positive trial may effect observing responses. The shorter the duration of the negative trial, the less the strength of observing responses.

\section{Discussion}

Experiment I demonstrated that preference for the observing response increased the longer the duration of the delay stimuli in a concurrent chains procedure. The data are in accordance with a prediction made by Wilton (1972) in his version of the information hypothesis of conditioned reinforcement.

The data of Experiment I show that the preference for the observing response is graded rather than all or none as a function of delay as implied by the findings of Lutz and Perkins (1960). There are several possibilities for explaining the discrepancies. Lutz and Perkins studied the acquisition of observing responses by rats in an E maze, while the present experiment studied steady state behavior of pigeons in an operant concurrent-chains procedure. There is, however, one salient difference which might be more important than the others. This is that the present experiment employed relative rate as the dependent variable. In Lutz and Perkins's study, a tum in one direction committed the animal to that altemative on a given trial. This is analogous to a concurrent chains procedure with a fixed ratio of one response in the initial component. This latter procedure might well have provided data showing that the animals chose the observing response on a high percentage of the trials under all delay conditions.
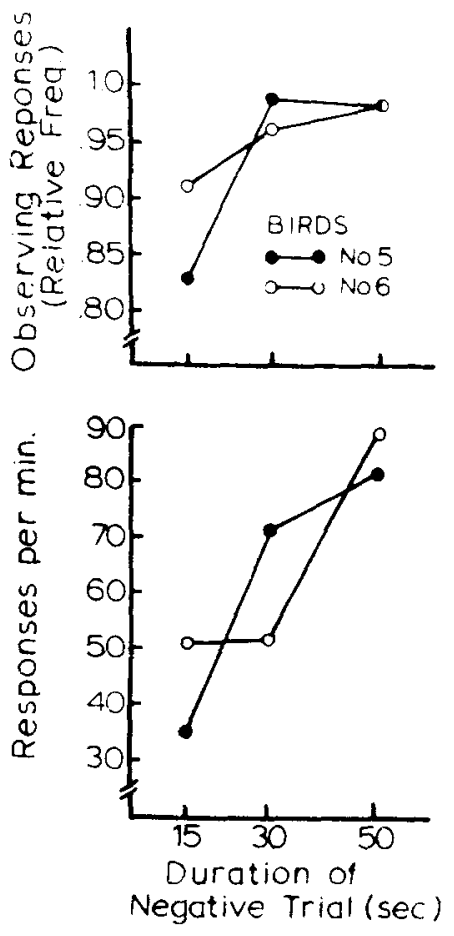

Figure 4. Relative frequency (lipper panel) and response rate (lower panel) of observing responses as a function of negative trial duration for Birds 5 and 6.

In Experiment II, it was shown that varying the duration of the negative trial in an observing response procedure may change the strength of observing responses. Generally, the longer the negative trial the stronger the observing response. Since the probability of either kind of trial remained constant at .50 , changes in the amount of information transmitted by a stimulus did not occur. Wilton's hypothesis of observing responses would seem to imply that the opposite result would be obtained; the longer the negative trial, the greater the punishment delivered by the stimulus associated with the negative trial. In his theory, the onset of a stimulus correlated with reinforcement reinforces observing responses but the onset of a stimulus correlated with nonreinforcement punishes observing responses.

The data from Experiment II point to the possibility that other experiments which varied the probability of positive trials (or more highly valued schedule components), have been misinterpreted. Since the amount of transmitted information is altered by changing trial probability, it has been supposed that changes in this variable are responsible for the change in strength of the observing response (Wilton, 1972). The present results point to the possibility that it is the amount of time spent in negative (or less highly valued) components that is responsible for the findings of experiments varying component probability.

On the other hand, Wilton (personal communication) 
suggests that an informational analysis may predict the results of Experiment II if we consider both the similarities and differences in what the positive and negative stimuli predict. When the negative trial is $10 \mathrm{sec}$, and the positive is 30 , the negative stimulus predicts a delay of approximately $10 \mathrm{sec}$; then, following that, the possibility $(p=.50)$ of a positive trial. The positive trial predicts an additional $20 \mathrm{sec}$ of delay plus food. When the negative trial is $50 \mathrm{sec}$ and the positive 30 , both stimuli predict a delay of at least $30 \mathrm{sec}$, with the negative signaling an additional $20 \mathrm{sec}$. In this latter case, the positive stimulus predicts a delay of $30 \mathrm{sec}$ plus food plus the possibility of a further positive trial, while the negative stimulus predicts no food and no further trials for $50 \mathrm{sec}$. Wilton's position is that the information in the positive stimulus is more valuable in the latter case since it makes a relatively more attractive prediction than when the negative trial is short.

A simpler hypothesis that the value of any positive stimulus is a function, in part, of the relative time spent in a less valuable condition is consistent with the facts without the addition of the rather elaborate predictive scheme outlined by Wilton. It is also consistent with other data from the area of conditioned reinforcement (e.g., Notterman, 1950). This hypothesis, which is a type of "contrast" hypothesis, is also consistent with the data from Experiment I.

Suppose that the value of either of the positive stimuli (white or green key keylights) in Experiment I was, in part, a function of the relative amount of time, for a given response key, that the animal spent in the presence of stimuli not directly associated with reinforcement. We might express this assumption by saying that the value of a stimulus is partly determined by the quantity $\mathrm{T}-/ \mathrm{T}+$, where $\mathrm{T}-$ is equal to the amount of time per presentation of a positive stimulus that the animal spends in stimuli not associated with reinforcement and $\mathrm{T}+$ is the amount of time per positive stimulus spent in the presence of the positive stimulus. On the observing key, T- will equal the amount of VI time plus the amount of time spent in the negative stimulus per positive stimulus. $\mathrm{T}+$ will equal the duration of the positive stimulus. On the nonobserving key, $\mathrm{T}$ - will be equal only to the VI time per positive stimulus since each presentation of the white light is potentially followed by reinforcement. The white light is a positive stimulus in which the probability of reinforcement is .50. $\mathrm{T}+$ on the nonobserving key will be equal to the duration of the white light (positive stimulus). Now if we express the value of the green light ( $S+$ on observing key) relative to the value of the white light (St on the nonobserving key) as the ratio $\left.\left(T--R_{0} / T+R_{0}\right) / T-N R_{0} / T+N R_{0}\right)$, where $R_{0}$ stands for the observing key, we will find that, as the delay interval (the independent variable in Experiment I) becomes shorter, this ratio becomes smaller, predicting less relative responding on the observing key.

The above formulation cannot serve as a complete model for predicting the results of Experiment I or other observing response experiments for several reasons. One is that the probability of reinforcement in the white light is not taken into account. Another is the uncertainty about how to compute the amount of VI time on a given key. (See Rachlin, 1973 for a discussion of time calculations in concurrent schedules. For present purposes, nominal variable-interval times have been used.) A third difficulty is that, as it stands, the prediction would be made that increasing the value of the VI schedule on one key would increase the preference for the stimulus on that key since $\mathrm{T}$ - on that key would increase, increasing the ratio $\mathrm{T}-/ \mathrm{T}+\mathrm{A}$ complete model would have to account for the effects of the decreased rate of reinforcement which would accompany the increase in T-. Nevertheless, the above formulation accounts in a general way for the results of Experiment $I$ and the results of an experiment by Hursh and Fantino (1974) who found that increasing the value of the initial-link VI schedules lessened the preference for the observing key. Again, assuming equal reinforcement rates and using nominal VI values, the ratio $\left(T-R_{0} / T+R_{0}\right) /\left(T-N R_{0} / T+N R_{0}\right)$ becomes smaller as the value of the initial VI links increases.

\section{REFERENCES}

Bower, G., McLean, J., \& Meacham, J. Value of knowing when reinforcement is due. Journal of Comparative and Physiological Psy chology, 1966, 62, 184-192.

Eckerman, D. A. Uncertainty reduction and conditioned reinforcement. The Psy chological Record, 1973, 23, 39-47.

Hendry, D. P. Reinforcing value of information: Fixed-ratio schedules. In D. P. Hendry (Ed.), Conditioned reinforcement. Homewood, Illinois: Dorsey, 1969. P. 300-341.

Hursh, S. R., \& Fantino, E. An appraisal of preference for multiple versus mixed schedules. Journal of the Experimental Analysis of Behavior, 1974, 22, 31-38.

Kendall, S. B. Redundant information in an observing-response procedure. Joumal of the Experimental Analy sis of Behavior, $1973,19,81-92$. (a)

Kendall, S. B. Effects of two procedures for varying information transmission on observing responses. Journal of the Experimental Analy sis of Behavior, 1973, 20, 73-83. (b)

Kendall, S. B. Preference for intermittent reinforcement. Journal of the Experimental Analysis of Behavior, 1974, 21, 463-473.

Lutz, R. E., \& Perkins, C. C. A time variable in the acquisition of observing responses. Journal of Comparative and Physiological Psychology, 1960, 53, 180-182.

McMichael, J. S., Lanzetta, J. T., \& Driscoll, J. Infrequent reward facilitates observing responses in rats. Psychonomic Science, 1967, 8, 23-24.

Notterman, J. M. A study of some relations between a periodic reinforcement and number of acquisition trials on conditioning and extinction. Journal of Experimental Psy chology, 1950, 41, 161-169.

Rachlin, H, Contrast and matching. Psychological Review, 1973, 80, 217-234.

wilton, $R$. $N$. The role of information in the emission of observing responses and partial acquisition phenomena. Learning and Motivation, 1972, 3, 479-499.

Wilton, R. N., \& Clements, R. O. The role of information in the emission of observing responses: A test of two bypotheses. Joumal of the Experimental Analysis of Behavior, 1971, 16, 161-166.

\section{REFERENCE NOTES}

1. Hendry, D. P. Reinforcing value of information. NASA 
Technical Report 65-1. Space Research Laboratory, University of Maryland, 1965.

2. McMillan, J. C. Uncertainty reduction and the maintenance of observing behavior. Paper presented at the meetings of the Psychonomic Society, San Antonio, 1970.

\section{NOTE}

Wilton's version of the information hypothesis. The interested reader should see his account for a full treatment of different hypotheses.
1. For present purposes, we will be concerned only with
(Received for publication June 25, 1974; revision accepted December $12,1974$. ) 